\title{
Management of Hangman's Fractures: A Systematic Review
}

\author{
Hamadi Murphy, MD, * Gregory D. Schroeder, MD,* Weilong J. Shi, MD,* \\ Christopher K. Kepler, MD, MBA,* Mark F. Kurd, MD,* Andrew N. Fleischman, MD,* \\ Frank Kandziora, MD, PhD, † Jens R. Chapman, MD, $\neq$ Lorin M. Benneker, MD, $\S$ \\ and Alexander R. Vaccaro, $M D, P h D, M B A^{*}$
}

\begin{abstract}
Background: Traumatic spondylolisthesis of the axis, is a common cervical spine fracture; however, to date there is limited data available to guide the treatment of these injuries. The purpose of this review is to provide an evidence-based analysis of the literature and clinical outcomes associated with the surgical and nonsurgical management of hangman's fractures.
\end{abstract}

Methods: A systematic literature search was conducted using PubMed (MEDLINE) and Scopus (EMBASE, MEDLINE, COMPENDEX) for all articles describing the treatment of hangman's fractures in 2 or more patients. Risk of nonunion, mortality, complications, and treatment failure (defined as the need for surgery in the nonsurgically managed patients and the need for revision surgery for any reason in the surgically managed patients) was compared for operative and nonoperative treatment methods using a generalized linear mixed model and odds ratio analysis.

Results: Overall, 25 studies met the inclusion criteria and were included in our quantitative analysis. Bony union was the principal outcome measure used to assess successful treatment. All studies included documented fracture union and were included in statistical analyses. The overall union rate for 131 fractures treated nonsurgically was $94.14 \%$ [ $95 \%$ confidence interval (CI), 76.15-98.78]. The overall union rate for 417 fractures treated surgically was $99.35 \%$ (95\% CI, 96.81-99.87). Chance of nonunion was lower in those patients treated surgically (odds ratio, $0.12 ; 95 \%$ CI, $0.02-0.71$ ). There was not a significant difference in mortality between patients treated surgically $(0.16 \% ; 95 \% \mathrm{CI}, 0.01 \%-2.89 \%)$ and nonsurgically $(1.04 \%$; $95 \% \mathrm{CI}$,

Accepted for publication June 21, 2017.

From the *Department of Orthopaedic Surgery, The Rothman Institute, Thomas Jefferson University, Philadelphia, PA, USA; †Center for Spine Surgery and Neurotraumatology, BG Unfallklinik Frankfurt am Main, Frankfurt, Germany; $\$$ Swedish Neuroscience Institute, Swedish Medical Center, Seattle, WA, USA; and §Spine Unit, Department for Orthopaedics and Traumatology, Inselspital, University of Bern, Bern, Switzerland.

C. K. Kepler receives research support from Biomet, Medtronic, and Pfizer and is on the editorial board of Clinical Spine Surgery. M. F. Kurd receives stock or stock options from Duratap, LLC, research support from Innovative Surgical Designs and is an ISASS Board Member and paid consultant for Stryker. The remaining authors report no conflict of interest.

Supplemental digital content is available for this article. Direct URL citations appear in the printed text and are provided in the HTML and PDF versions of this article on the journal's Web site (www.jorthotrauma.com).

Reprints: Gregory D. Schroeder, MD, Department of Orthopedic Surgery, Thomas Jefferson University and the Rothman Institute, 925 Chestnut St, 5th Floor, Philadelphia, PA 19107, USA (e-mail: gregdschroeder@gmail. com).

Copyright (C) 2017 Wolters Kluwer Health, Inc. All rights reserved.

DOI: 10.1097/BOT.0000000000000952
$0.08 \%-11.4 \%$ ) (odds ratio, $0.15 ; 95 \%$ CI, $0.01-2.11$ ). Treatment failure was less likely in the surgical treatment group $(0.12 \% ; 95 \% \mathrm{CI}$, $0.01 \%-2.45 \%)$ than the nonsurgical treatment group $(0.71 \% ; 95 \% \mathrm{CI}$, $0.28 \%-15.75 \%$ ) (odds ratio $0.07 ; 95 \% \mathrm{CI}, 0.01-0.56$ ).

Conclusion: Hangman's fractures are common injuries, and surgical treatment leads to an increase in the rate of osteosynthesis/fusion without significantly increasing the rate of complication. Both an anterior and a posterior approach result in a high rate of fusion, and neither approach seems to be superior.

Key Words: Hangman's fracture, traumatic spondylolithesis, C2 fracture, upper cervical spine fracture, axis fracture

(J Orthop Trauma 2017;31:S90-S95)

\section{INTRODUCTION}

Traumatic spondylolisthesis of the axis, also commonly know by its eponym, a hangman's fracture, is due to a bilateral fracture of the $\mathrm{C} 2$ pars interarticularis. These injuries account for $4 \%-7 \%$ of all cervical spine fractures and $20 \%-22 \%$ of axis fractures. ${ }^{1-3}$ In 1965, Schneider coined the term "Hangman's fracture" to describe this fracture pattern because of the similarities seen in the fractures associated with judicial hangings ${ }^{4}$; however, it has been found that this fracture pattern is only seen in about $10 \%$ of injuries associated with hangings. ${ }^{5}$ Since then, several classification schemes for hangman's fractures have been developed that help guide treatment decisions. The original classification system was first developed by Effendi and later modified by Levine and Edwards. ${ }^{6}$

The Levine-Edwards classification system is the most used classification system, and it classifies fractures based on the mechanism of injury. Type I fractures are the result of a hyperextension-axial loading force, whereas type II fractures most likely result from a combined hyperextension-axial loading force, with an additional anterior flexion and compression force. Type IIA and type III fractures are the result of a primary flexion force. ${ }^{6}$ Type I injuries are considered stable, whereas type II, IIA, and III injuries are unstable as they usually involve ruptures of the $\mathrm{C} 2 / 3$ disk and anterior and posterior longitudinal ligament involvement (Fig. 1). In addition to these fracture types, there is an atypical variant first identified by Starr and Eismont. ${ }^{7}$ In the atypical variant, the fracture produces canal compromise rather than canal expansion. ${ }^{7}$

Although hangman's fractures are a relatively common fracture, there is a paucity of high-quality studies available on this injury to help establish an evidence-based treatment 


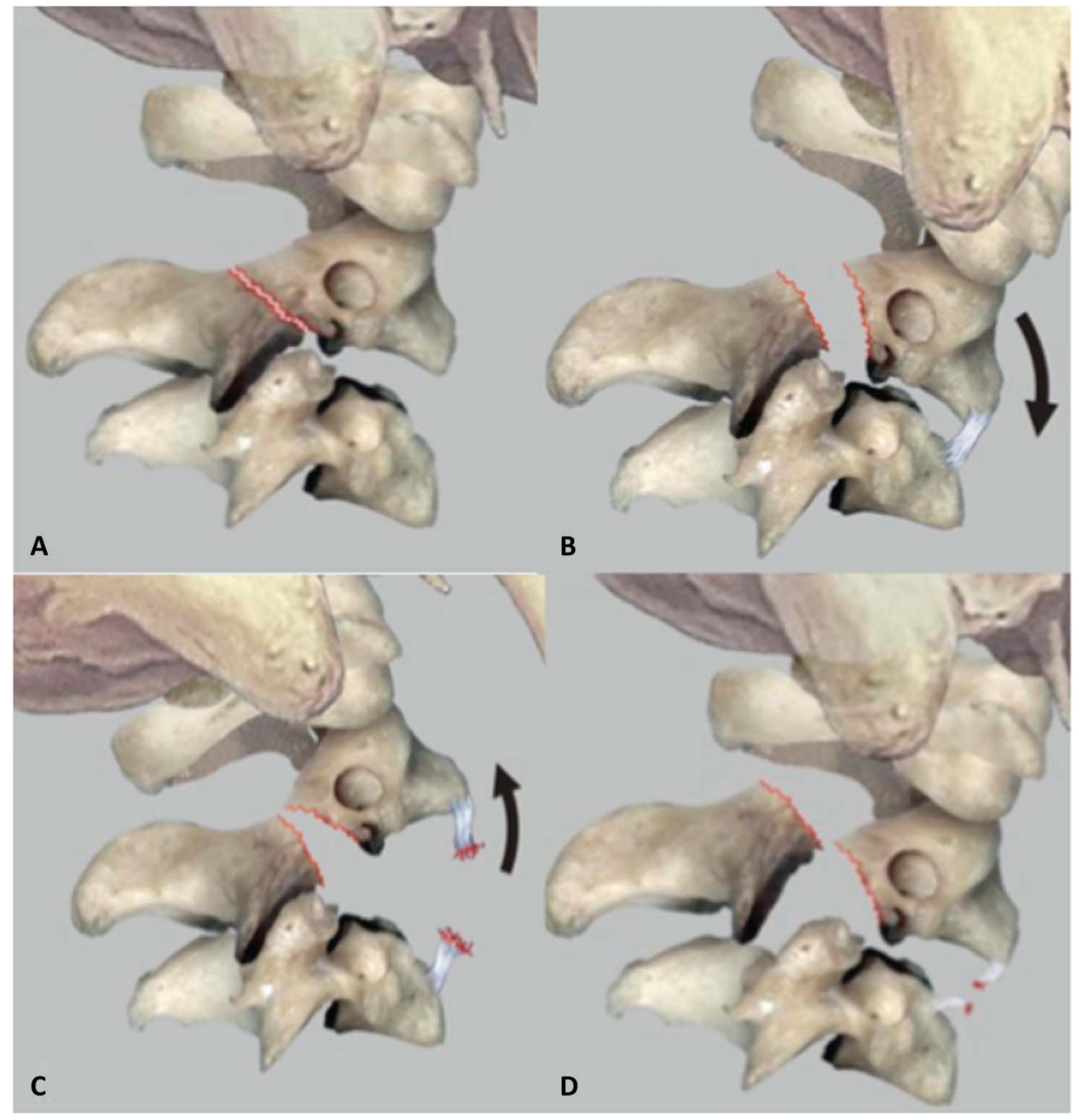

FIGURE 1. Visual representation of Levine-Edwards fracture classification. (A) Levine/Edwards type 1, (B) type II, (C) type IIA, and (D) type III. Arrows demonstrate the direction of displacement.

algorithm. Conventional practice dictates that stable type I injuries can be treated nonsurgically with either a hard collar or rigid immobilization, ${ }^{8}$ whereas unstable fractures may benefit from surgical intervention. ${ }^{9}$ The purpose of this review is to provide an evidence-based analysis of the literature and clinical outcomes associated with the surgical and nonsurgical management of hangman's fractures.

\section{MATERIALS AND METHODS}

The optimal treatment for hangman's fractures was evaluated through an evidence-based systematic review of the literature. The literature search was conducted using PubMed (MEDLINE) and Scopus (EMBASE, MEDLINE, COMPENDEX). The search was performed using various combinations of the search terms "axis, cervical," "vertebra, injuries," "vertebra, surgery," "spinal fractures," "spondylolisthesis," "Hangman's fracture," "Traumatic spondylolisthesis of axis," "Traumatic spondylolisthesis of $\mathrm{C} 2$," "C2 pars interarticularis fracture," "Cervical spondylolisthesis," "ACDF," "anterior cervical discectomy and fusion," "rigid cervical collar," "halo," "posterior fixation and fusion." The search returned 2904 results after removing duplicates. The title and abstract of each study was screened initially for relevance, and then full-text manuscripts were reviewed against specific inclusion criteria by 2 independent reviewers (H.A.M. and W.J.S.). This resulted in 22 articles that met the inclusion criteria and were included in our study. In addition, the reference lists of all articles included were reviewed to ensure a comprehensive search had been completed. This resulted in an additional 3 articles (Fig. 2).

In the circumstances that multiple studies reported on the same patient cohort, the most recent study was included in our analysis. The 25 studies selected based on the above methods were used as evidence for this review. All studies were assigned a level of evidence using the evidence grading tool developed by the Centre for Evidence-Based Medicine in Oxford, United Kingdom. ${ }^{10}$ In addition, we conducted a bias analysis of all studies included with the criteria recommended by the Cochrane Back Review Group, and studies were considered to have an overall low risk of bias when at least 6 of the individual criteria were determined to have a low risk of bias. ${ }^{11}$

\section{INCLUSION AND EXCLUSION CRITERIA}

The principal requirement for inclusion was the reporting of data describing the treatment of hangman's fractures in 


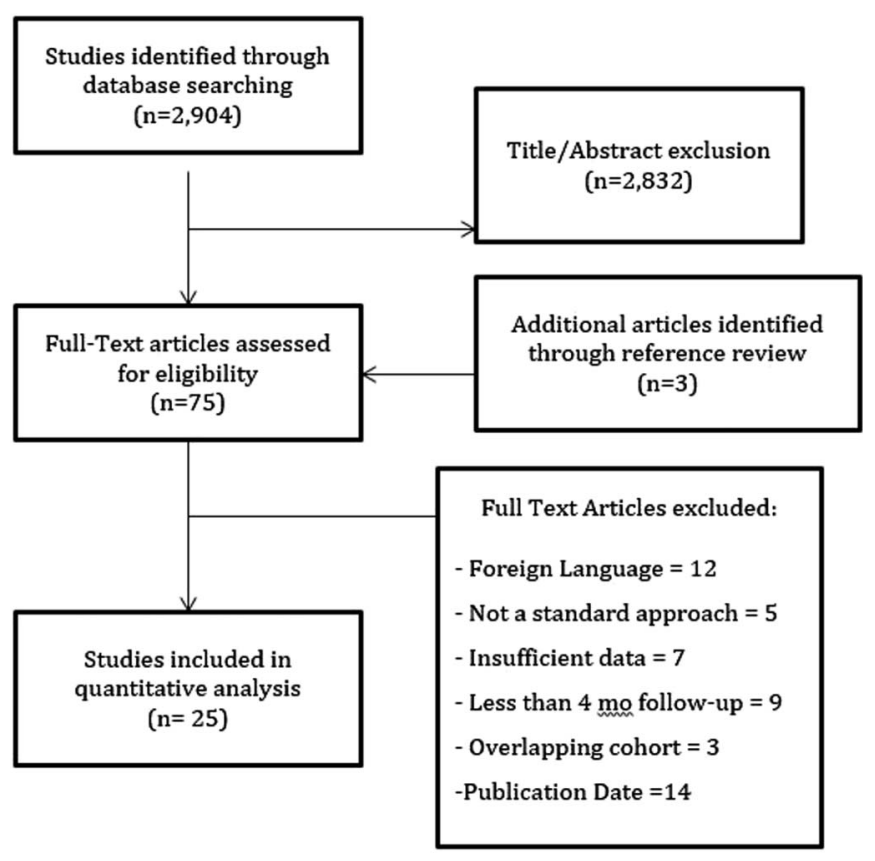

FIGURE 2. Schematic representation of the literature search performed.

2 or more patients. This review included studies reporting all 4 classes of hangman's fractures, Levine-Edwards types I, II, IIA, and III, as well as those associated with additional injuries to the spine. All literature published in English as well as non-English studies that were readily available and translated into English were included. Studies were excluded if they did not provide at least minimal details regarding fracture classification, treatment (surgical or nonsurgical), and outcome (bony union rate). The review was limited to adults older than 18 years. Studies using cadavers, nonhuman subjects, or laboratory simulations were excluded. In addition, studies without a clear methodology were excluded.

\section{STATISTICAL ANALYSIS}

The only consistently reported outcome measure in all studies was fracture union or the lack thereof, referred to by various terms including pseudarthrosis, nonunion, or fibrous union. Risk of nonunion, mortality, complications, and treatment failure (defined as the need for surgery in the nonsurgically managed patients and the need for revision surgery for any reason in the surgically managed patients) was compared for operative and nonoperative treatment methods using a generalized linear mixed model and odds ratio analysis. It was the intention of the authors to also compare patients based on the Levine-Edwards Types; however, the existing literature was not sufficient to perform a meaningful subgroup analysis.

\section{RESULTS}

Overall, 25 studies met the inclusion criteria and were included in our quantitative analysis. These 25 articles reported hangman's fractures treated either surgically or nonsurgically.
Of the studies included, there were 19 level III studies and 6 level IV studies. Out of the 25 studies included, none had an overall low risk of bias (see Appendix A, Supplemental Digital Content 1, http://links.lww.com/JOT/A46). A total of 548 fractures are included in our analysis (Table 1). The mean age of all cases is 38.2 (range 18-82) years. Of the 548 fractures, $46(8.4 \%)$ were identified as type I, $228(41.6 \%)$ were type II, $89(16.2 \%)$ were type IIA, and $35(6.4 \%)$ were type III fractures using the Levine-Edwards classification. One hundred fifty $(27.4 \%)$ fractures were not broken down by classification. One hundred thirty-one (24\%) cases were treated nonsurgically and $417(76 \%)$ were treated surgically.

The most commonly used method of nonsurgical treatment was the halo vest, which was used in $86(15.7 \%)$ cases. The Minerva jacket and hard collar were used in the 45 $(8.2 \%)$ remaining cases treated nonsurgically. No difference in union rate, mortality rate, treatment failure, or complications was seen in patients treated with a rigid cervical orthosis versus a halo vest (Table 2).

In the literature, surgical procedures were documented as anterior cervical discectomy and fusion (ACDF), posterior fixation and fusion, or the combined anterior-posterior approach. Two hundred (36.5\%) fractures were treated with an ACDF, 193 (35.2\%) were treated with a posterior fixation and fusion, and $24(4.4 \%)$ fractures were treated with a combined anterior-posterior approach. Similar to the nonoperative data, no difference in union rate, mortality rate, treatment failure, or complications was seen in the different surgical groups (Table 3).

Bony union was the principal outcome measure used to assess successful treatment. All studies included documented fracture union and were included in statistical analyses. The overall union rate for 131 fractures treated nonsurgically was 94.14\% [95\% confidence interval (CI), 76.15-98.78]. The overall union rate for 417 fractures treated surgically was $99.35 \%$ (95\% CI, 96.81-99.87). Chance of nonunion was lower in those patients treated surgically (odds ratio, $0.12 ; 95 \%$ CI, 0.02-0.71).

There was not a significant difference in mortality between patients treated surgically $(0.16 \% ; 95 \% \mathrm{CI}, 0.01 \%-2.89 \%)$ and nonsurgically $(1.04 \%$; $95 \% \mathrm{CI}, 0.08 \%-11.4 \%)$ (odds ratio, 0.15 ; 95\% CI, 0.01-2.11). Treatment failure was less likely in the surgical treatment group $(0.12 \% ; 95 \% \mathrm{CI}, 0.01 \%-2.45 \%)$ than the nonsurgical treatment group $(0.71 \%$; $95 \%$ CI, $0.28 \%$ $15.75 \%$ ) (odds ratio $0.07 ; 95 \%$ CI, $0.01-0.56$ ). In those patients treated nonsurgically there were 7 reported complications, and in patients treated with surgery there were 17 reported complications; because of the lack of consistency in the reporting, and the scarcity of complications, no statistical analysis was able to be performed on the individual complications, but the raw data are presented in Table 4. A mixed-effect poisson model was used to calculate the overall rate of expected complications per patient. For nonsurgical patients there were $0.13(95 \%$ CI, 0.015-1.10) expected complications per patient and for those treated surgically, $0.087(95 \% \mathrm{CI}, 0.019-0.403)$ complications expected per patient. This difference was not significant $(P=0.675)$.

\section{DISCUSSION}

A thorough search and review of the literature on hangman's fracture outcomes was completed to provide 
TABLE 1. Treatment and Outcome of Hangman's Fractures: Cases Reported in the Literature

\begin{tabular}{|c|c|c|c|c|c|c|c|c|}
\hline References & $\begin{array}{l}\text { Level of } \\
\text { Evidence }\end{array}$ & $\begin{array}{c}\text { Total } \\
\text { Patients } \\
(\mathrm{M} / \mathrm{F})\end{array}$ & $\begin{array}{l}\text { Mean Age } \\
\text { (Range) }\end{array}$ & $\begin{array}{c}\text { Mean } \\
\text { Follow -Up, } \\
\text { mo }\end{array}$ & Nonsurgical/Surgical & $\begin{array}{c}\text { Union/ } \\
\text { Nonunion }\end{array}$ & $\begin{array}{l}\text { Treatment } \\
\text { Failure }\end{array}$ & Deaths \\
\hline Boullosa et $\mathrm{al}^{18}$ & 4 & $10(8 / 2)$ & $35.7(21-52)$ & 27.8 & none/10 PCDF & $10 / 0$ & 0 & 0 \\
\hline Dalbaryak et al ${ }^{19}$ & 4 & $4(3 / 1)$ & $34(23-47)$ & 24 & none/4 PCDF & $4 / 0$ & 0 & 0 \\
\hline Elmiligui et $\mathrm{al}^{20}$ & 3 & $15(9 / 6)$ & $37(22-61)$ & 32 & none/15 PCDF & $15 / 0$ & 0 & 0 \\
\hline Ge et $\mathrm{al}^{1}$ & 3 & $38(25 / 13)$ & $37.6(19-65)$ & 42 & none/24 ACDF, $14 \mathrm{PCDF}$ & $38 / 0$ & 0 & 0 \\
\hline Hakalo et al (2008) & 3 & $8(* / *)$ & $27(18-47)$ & 28 & none/8 PCDF & $8 / 0$ & 0 & 0 \\
\hline Jeong et $\mathrm{al}^{21}$ & 3 & $13(8 / 5)$ & $43(18-64)$ & 17.2 & none/13 PCDF & $13 / 0$ & 1 & 0 \\
\hline Li et $\mathrm{al}^{22}$ & 3 & $38(20 / 18)$ & $42.8(20-69)$ & 49.2 & none/38 ACDF & $36 / 2$ & 0 & 0 \\
\hline Liu et $\mathrm{al}^{15}$ & 4 & $13(10 / 3)$ & $39.4(23-48)$ & 12 & none/1 ACDF, 12 Ant-post & $13 / 0$ & 0 & 0 \\
\hline Ma et $\mathrm{al}^{16}$ & 4 & $35(21 / 14)$ & $45(21-71)$ & 44 & none/35 PCDF & $35 / 0$ & 0 & 0 \\
\hline Moon et $\mathrm{al}^{23}$ & 4 & $20(* / *)$ & $*(26-57)$ & 12 & none/16 ACDF, 4 PCDF & $20 / 0$ & 0 & 0 \\
\hline Muller et al ${ }^{13}$ & 4 & $37(* / *)$ & $37.6(18-70)$ & 44.2 & $\begin{array}{l}16 \text { rigid orthosis, } 15 \text { Halo/2 } \\
\text { ACDF, } 5 \text { PCDF, } 1 \text { Ant-Post }\end{array}$ & $33 / 1$ & 5 & 0 \\
\hline Rajasekaran et $\mathrm{al}^{24}$ & 3 & $20(18 / 2)$ & $38(18-63)$ & 29 & none/20 ACDF & $18 / 2$ & 0 & 1 \\
\hline Ramieri et $\mathrm{al}^{25}$ & 3 & $16(13 / 3)$ & $33.7(19-53)$ & 32 & 11 Halo, 5 rigid orthosis/none & $16 / 0$ & 0 & 2 \\
\hline Robertson et $\mathrm{al}^{26}$ & 3 & $36(24 / 12)$ & $46(18-82)$ & 45.6 & 27 Halo, 9 rigid orthosis/none & $36 / 0$ & 4 & 0 \\
\hline References & $\begin{array}{c}\text { Level of } \\
\text { Evidence }\end{array}$ & $\begin{array}{c}\text { Total Patients } \\
(\mathrm{M} / \mathrm{F})\end{array}$ & $\begin{array}{l}\text { Mean Age } \\
\text { (Range) }\end{array}$ & $\begin{array}{r}\text { Mean Fol } \\
-\mathbf{U p}, \mathbf{m}\end{array}$ & $\begin{array}{c}\text { Nonoperative/ } \\
\text { Operative }\end{array}$ & $\begin{array}{c}\text { Union/ } \\
\text { Nonunion }\end{array}$ & $\begin{array}{c}\text { Treatment } \\
\text { Failure }\end{array}$ & Deaths \\
\hline Salunke et $\mathrm{al}^{27}$ & 3 & $11(8 / 3)$ & $28.8(18-40)$ & 24.8 & $2 \mathrm{Halo} / 9 \mathrm{PCDF}$ & $8 / 3$ & 1 & 0 \\
\hline Samaha et $\mathrm{al}^{28}$ & 3 & $24(13 / 11)$ & $40(18-75)$ & 13 & $\begin{array}{l}15 \text { rigid orthosis } / 9 \\
\text { PCDF }\end{array}$ & $23 / 1$ & 0 & 0 \\
\hline Shin et $\mathrm{al}^{29}$ & 3 & $23(15 / 8)$ & 46.4 & 28.9 & none/23 PCDF & $23 / 0$ & 0 & 0 \\
\hline Taller et $\mathrm{al}^{30}$ & 3 & $10(8 / 2)$ & $44.8(21-71)$ & 33.3 & none/10 PCDF & $10 / 0$ & 0 & 0 \\
\hline Tian et $\mathrm{al}^{31}$ & 3 & $14(11 / 3)$ & $38.2(21-59)$ & 28.7 & none/14 PCDF & $14 / 0$ & 0 & 0 \\
\hline Vaccaro et $\mathrm{al}^{14}$ & 3 & $31(16 / 15)$ & $38.3(19-77)$ & 17 & $31 \mathrm{Halo} /$ none & $25 / 6$ & 0 & 0 \\
\hline Wang et $\mathrm{al}^{32}$ & 3 & $11(8 / 3)$ & $34(20-62)$ & 17 & none/11 ACDF & $11 / 0$ & 0 & 0 \\
\hline Wei et $\mathrm{al}^{33}$ & 3 & $49(30 / 19)$ & $40.9(26-49)$ & 50.3 & none/49 ACDF & $49 / 0$ & 0 & 0 \\
\hline Ying et $\mathrm{al}^{34}$ & 3 & $30(19 / 11)$ & $32(18-67)$ & 12 & none/30 ACDF & $30 / 0$ & 0 & 0 \\
\hline Xie et $\mathrm{al}^{35}$ & 3 & $29(* / *)$ & $41.4(24-71)$ & 33.6 & none/29 ACDF & $29 / 0$ & 0 & 0 \\
\hline Wang et $\mathrm{al}^{17}$ & 3 & $11(8 / 3)$ & $39(21-56)$ & 30.1 & none/11 Ant-Post & $11 / 0$ & 0 & 0 \\
\hline
\end{tabular}

*Not reported.

PCDF, Posterior cervical decompression and fusion.

evidence-based decisions in their treatment. Our study indicates that surgery significantly improves the rate of osteosynthesis or fusion and is not associated with an increase risk of mortality or complications. Although this study was unable to separate patients by fracture type, this finding is especially important, as it is probable that the fractures that were treated surgically were more severe injuries, and thus at a higher risk of nonunion at the time of the injury than those treated nonoperatively. Furthermore, this study finds no difference in any outcome measure based on the type of surgery performed or the type of nonoperative treatment used.
The current analysis of the literature on hangman's fractures included literature from 2000 and onward; this time frame was done because there were significant advances in segmental posterior cervical instrumentation that had gained wide spread acceptance by 2000 , and so including literature before 2000 may have significantly biased the literature against posterior cervical fixation. Before the development of segmental posterior fixation, multiple studies reported the efficacy of nonoperative treatment and stratified the results by the fracture type. It was the authors' intention to stratify treatment based on the Levine and Edwards fracture type; however, very few

TABLE 2. Treatment of Hangman's Fractures: Patients Treated Nonsurgically

\begin{tabular}{lccccc}
\hline Treatment Method & No. Patients & Union/Nonunion & Treatment Failure & Deaths & Complications \\
\hline Rigid orthosis* & 45 & $42 / 3$ & 0 & 0 & 1 \\
Halo & 86 & $75 / 11$ & 5 & 2 & 6 \\
$P$ & & 0.38 & 0.16 & 0.55 & 0.42 \\
\hline
\end{tabular}

*Rigid orthosis includes hard collar, Minerva Jacket, and SOMI. 
TABLE 3. Treatment of Hangman's Fractures: Patients Treated Surgically

\begin{tabular}{lccccc}
\hline Procedure & No. Patients & Union/Non-Union & Treatment Failure & Deaths & Complications \\
\hline ACDF & 200 & $196 / 4$ & 0 & 1 & 13 \\
PCDF & 193 & $191 / 2$ & 1 & 0 & 4 \\
A/PCDF & 24 & $23 / 1$ & 0 & 0 & 0.53 \\
$P$ & & 0.23 & 0.84 & 0.28 \\
\hline
\end{tabular}

PCDF, Posterior cervical decompression and fusion.

contemporary studies reported individual patient data with the type of hangman's fracture, the treatment, and the success of the specific patient. Instead, all types of injuries were often grouped together into operative or nonoperative treatment. Because of this, it is important to look at the results of this study in context with the results of classic literature. In a systematic review that included all PubMed-cited articles between 1966 and 2002, Li et al ${ }^{12}$ reported that Levine-Edwards type I injuries had a nonoperative healing rate of $100 \%$, LevineEdwards type II had a $60 \%$ rate, and type III had less than a $40 \%$ healing rate. These results are important when interpreting the result of the current study that surgical treatment increases the rate of osteosynthesis/fusion by 9 -fold. Given the fact that type I injuries have a healing rate approaching 100\% with nonoperative treatment, it is unlikely that surgical intervention improves this; conversely, the effect of surgery may be underestimated in the current study for type II, IIa, and III fractures, as the analysis also included type I factures.

When surgery is performed, this study found no difference in fusion rates, complications, mortality, or treatment failure when patients are treated with an ACDF, a posterior fusion or a combined anterior-posterior fusion. Because of this,

TABLE 4. Reported Complications Broken Down by Treatment Method

\begin{tabular}{|c|c|c|}
\hline Treatment & $\begin{array}{l}\text { No. } \\
\text { Complications }\end{array}$ & Detailed Diagnosis \\
\hline \multirow[t]{5}{*}{$\mathrm{ACDF}$} & 13 & Wound infection (3) \\
\hline & & Neurologic deficit (3) \\
\hline & & Hematoma (2) \\
\hline & & $\begin{array}{l}\text { Prolonged pain at iliac crest donor } \\
\text { site (4) }\end{array}$ \\
\hline & & Loose or broken hardware (1) \\
\hline \multirow[t]{5}{*}{ PCDF } & 4 & \\
\hline & & Wound infection (1) \\
\hline & & Loose or broken hardware (1) \\
\hline & & Vertebral artery injury (1) \\
\hline & & Death (1) \\
\hline \multirow[t]{2}{*}{ Rigid orthosis } & 1 & \\
\hline & & Skin breakdown from collar (1) \\
\hline \multirow[t]{5}{*}{ Halo } & 6 & \\
\hline & & Wound infection (1) \\
\hline & & Intracranial abscess (1) \\
\hline & & Loose or broken hardware (2) \\
\hline & & Deaths (2) \\
\hline
\end{tabular}

PCDF, Posterior cervical decompression and fusion. the approach should be determined based on surgeon and patient factors. In the authors practice, if a $\mathrm{C} 2$ pedicle screw is possible with the intended goal of lagging back the $\mathrm{C} 2$ vertebral body, an isolated bilateral $\mathrm{C} 2$ pedicle construct or a $\mathrm{C} 2-\mathrm{C} 3$ posterior cervical fusion is performed; however, if the fracture is so severe that $\mathrm{C} 2$ pedicle screws are not possible, in a young patient a $\mathrm{C} 2-3 \mathrm{ACDF}$ is performed, and in an elderly patient a $\mathrm{C} 1-\mathrm{C} 3$ posterior cervical fusion is performed.

There are significant limitations to this study, including all of those inherent to any systematic review. Specifically, the results of this analysis are only as accurate as the existing literature, and none of the 25 studies included had an overall low risk of bias. Furthermore, only 2 prospective studies are available on the treatment of hangman's fractures in the contemporary literature. Another significant limitation is the lack of individual patient data reported in the literature, and this prevented a meaningful subgroup analysis on how fracture type affects healing. Furthermore, complications were sparsely reported. It is likely that the analysis of the complications is accurate for major complications but does not reflect the development of minor complications. In the 25 studies included in the study, there were no reports of dysphagia/dysphonia after an ACDF, and only a single pin site infection from the use of a halo was reported.

\section{CONCLUSION}

Hangman's fractures are common injuries, and surgical treatment leads to an increase in the rate of osteosynthesis/ fusion without significantly increasing the rate of complication. Both an anterior and a posterior approach result in a high rate of fusion, and neither approach seems to be superior. The choice of anterior versus posterior should be made on a patient and surgeon specific basis.

\section{REFERENCES}

1. Ge $\mathrm{C}, \mathrm{Hao} \mathrm{D}, \mathrm{He} \mathrm{B}$, et al. Anterior cervical discectomy and fusion versus posterior fixation and fusion of $\mathrm{C} 2-3$ for unstable Hangman's fracture. J Spinal Disord Tech. 2015;28:E61-E66.

2. Gehweiler JA, Clark WM, Schaaf RE, et al. Cervical spine trauma: the common combined conditions. Radiology. 1979;130:77-86.

3. Al-Mahfoudh R, Beagrie C, Woolley E, et al. Management of typical and atypical hangman's fractures. Glob Spine J. 2015;6(5 suppl 1): 248-256.

4. Schneider RC, Livingston KE, Cave AJ, et al. "HANGMAN'S fracture" of the cervical spine. $J$ Neurosurg. 1965;22:141-154.

5. James R, Nasmyth-Jones R. The occurence of cervical fractures in victimes of judicial hanging. Forensic Sci Int. 1992;54:81-91.

6. Levine A, Edwards C, Maryland B. The management of traumatic spondylolisthesis of the axis. J Bone Joint Surg Am. 1985;67:217-226. 
7. Starr J, Eismont F. Atypical Hangman's fractures. Spine (Phila Pa 1976). 1993;18:1954-1957.

8. Greene KA, Dickman CA, Marciano FF, et al. Acute axis fractures: analysis of management and outcome in 340 consecutive cases. Spine (Phila Pa 1976). 1997;22:1843-1852.

9. Schleicher P, Scholz M, Pingel A, et al. Traumatic spondylolisthesis of the axis vertebra in adults. Glob Spine J. 2015;5:346-358.

10. JBJS Reviews. Available at: http://reviews.jbjs.org/instructions-forauthors\#levelsofevidence. Accessed August 1, 2016.

11. Furlan AD, Malmivaara A, Chou R, et al. 2015 updated method guideline for systematic reviews in the Cochrane back and neck group. Spine (Phila Pa 1976). 2015;40:1.

12. Li XF, Dai LY, Lu H, et al. A systematic review of the management of hangman's fractures. Eur Spine J. 2006;15:257-269.

13. Müller EJ, Wick M, Muhr G. Traumatic spondylolisthesis of the axis: treatment rationale based on the stability of the different fracture types. Eur Spine J. 2000;9:123-128.

14. Vacccaro AR, Madigan L, Bauerle WB, et al. Early halo immobilization of displaced traumatic spondylolisthesis of the axis. Spine (Phila Pa 1976). 2002;27:2229-2233.

15. Liu J, Li Y, Wu Y. One-stage posterior $\mathrm{C} 2$ and $\mathrm{C} 3$ pedicle screw fixation or combined anterior $\mathrm{C} 2-\mathrm{C} 3$ fusion for the treatment of unstable hangman's fracture. Exp Ther Med. 2013;5:667-672.

16. Ma W, Xu R, Liu J, et al. Posterior short-segment fixation and fusion in unstable Hangman's fractures. Spine (Phila Pa 1976). 2011;36: 529-533.

17. Wang J, Chen $\mathrm{H}$, Cao $\mathrm{P}$, et al. Combined anterior-posterior fixation and fusion for completely dislocated Hangman's fracture. Clin Spine Surg. 2016. [epub ahead of print].

18. Boullosa JLR, Colli BO, Carlotti CG, et al. Surgical management of axis' traumatic spondylolisthesis: hangman's fracture. Arq Neuropsiquiatr. 2004;62:821-826.

19. Dalbarak S, Yilmaz M, Firdin M, et al. Traumatic spondylolisthesis of the axis treated with direct $\mathrm{C} 2$ pars screw tezisinde direkt $\mathrm{C} 2$ pars vidas > ile. Turk Neurosurg. 2009;2:163-167.

20. ElMiligui Y, Koptan W, Emran I. Transpedicular screw fixation for type II Hangman's fracture: a motion preserving procedure. Eur Spine J. 2010;19:1299-1305.

21. Jeong DH, You NK, Lee CK, et al. Posterior C2-C3 fixation for unstable hangman's fracture. Korean J Spine. 2013;10:165-169.
22. Li Z, Li F, Hou S, et al. Anterior discectomy/corpectomy and fusion with internal fixation for the treatment of unstable hangman's fractures: a retrospective study of 38 cases. J Neurosurg Spine. 2015;22:387-393.

23. Moon M, Moon J, Moon Y, et al. Traumatic spondylolisthesis of the axis: 42 cases. Bull Hosp Jt Dis. 2001;60:61-66.

24. Rajasekaran S, Tubaki VR, Shetty AP. Results of direct repair of type 2 hangman fracture using Iso-C3D navigation: 20 cases. $J$ Spinal Disord Tech. 2012;25:E134-E139.

25. Ramieri A, Domenicucci M, Landi A, et al. Conservative treatment of neural arch fractures of the axis: computed tomography scan and X-ray study on consolidation time. World Neurosurg. 2011;75:314-319.

26. Robertson I, Vioreanu M, O'Toole G, et al. Functional outcome following traumatic spondylolisthesis of the axis. Eur J Orthop Surg Traumatol. 2006;16:110-113.

27. Salunke P, Sahoo SK, Krishnan P, et al. Are C2 pars-pedicle screws alone for type II Hangman's fracture overrated? Clin Neurol Neurosurg. 2016;141:7-12.

28. Samaha C, Lazennec JY, Laporte C, et al. Hangman's fracture: the relationship between asymmetry and instability. J Bone Joint Surg Br. 2000;82:1046-1052.

29. Shin JJ, Kim SH, Cho YE, et al. Primary surgical management by reduction and fixation of unstable hangman's fractures with discoligamentous instability or combined fractures: clinical article. J Neurosurg Spine. 2013;19:569-575.

30. Taller S, Suchomel P, Lukás R, et al. CT-guided internal fixation of a hangman's fracture. Eur Spine J. 2000;9:393-397.

31. Tian W, Weng C, Liu B, et al. Posterior fixation and fusion of unstable Hangman's fracture by using intraoperative three-dimensional fluoroscopy-based navigation. Eur Spine J. 2012;21:863-871.

32. Wang $\mathrm{C}, \mathrm{Ma} \mathrm{H}$, Yuan $\mathrm{W}$, et al. Anterior $\mathrm{C} 3$ corpectomy and fusion for complex Hangman's fractures. Int Orthop. 2013;37:89-93.

33. Wei F, Pan X, Zhou Z, et al. Anterior-only stabilization using cage versus plating with bone autograft for the treatment of type II/IIA Hangman's fracture combined with intervertebral disc injury. J Orthop Surg Res. 2015;10:33.

34. Ying Z, Wen Y, Xinwei W, et al. Anterior cervical discectomy and fusion for unstable traumatic spondylolisthesis of the axis. Spine (Phila Pa 1976). 2008;33:255-258.

35. Xie N, Khoo LT, Yuan W, et al. Combined anterior C2-C3 fusion and C2 pedicle screw fixation for the treatment of unstable Hangman's fracture: a contrast to anterior approach only. Spine (Phila Pa 1976). 2010;35:613-619. 